\title{
A FUZZY APPROACH FOR ADAPTIVE REUSE SELECTION OF INDUSTRIAL BUILDINGS IN HONG KONG
}

\author{
Yongtao TAN ${ }^{\mathrm{a}, *}$, Li-yin SHEN ${ }^{\mathrm{b}}$, Craig LANGSTON ${ }^{\mathrm{c}}$ \\ ${ }^{a}$ Department of Building and Real Estate, The Hong Kong Polytechnic University, Hung Hom, Kowloon, \\ Hong Kong SAR, China \\ ${ }^{b}$ Faculty of Construction Management and Real Estate, Chongqing University, Chongqing, 400044 \\ China \\ ${ }^{c}$ Institute of Sustainable Development and Architecture, Bond University Robina, QLD 4229 Australia
}

Received 12 April 2012; accepted 19 November 2012

\begin{abstract}
With rapid economic development and restructuring, there are an increasing number of aged or obsolete buildings in large cities, such as Hong Kong. Adaptive reuse of these buildings provides an alternative for property stakeholders towards more sustainable practices instead of redevelopment or destruction. Adaptive reuse can also make great contributions to sustainable development by reducing construction waste and saving natural resources. As a result of industrial restructuring, manufacturing plants were migrated from Hong Kong to Mainland China during the 1980s and 1990s. Many industrial buildings then became vacant or under-utilised. Adaptive reuse of these industrial buildings is considered a viable way forward for all parties, including government, property stakeholders and the community. However, the problem is how to deal with multiple criteria to assess how these buildings can be reused for residential living, retail, training centres, or other purposes. Adaptive reuse of industrial buildings is discussed in this paper, and a fuzzy adaptive reuse selection model is developed for decision-making. A hypothetical example is used to demonstrate the application of the method and show its effectiveness.
\end{abstract}

KEYWORDS: Adaptive reuse; Fuzzy approach; Industrial building; Decision making; Multiple selection criteria

REFERENCE to this paper should be made as follows: Tan, Y.; Shen, L.; Langston, C. 2014. A fuzzy approach for adaptive reuse selection of industrial buildings in Hong Kong, International Journal of Strategic Property Management 18(1): 66-76.

\section{INTRODUCTION}

As one of the most densely populated places in the world, Hong Kong has a well developed property market. The property market comprises four sectors, including residential, office, commercial and industrial space (private flatted factories, industrial/office, specialised factories and storage). As a result of industrial restructuring during the 1980s and $1990 \mathrm{~s}$, financial services, trading and logistics, tourism, and producer and professional services became emerging industries for the Hong Kong economy. Most manufacturing plants were moved to mainland China and there was little need for

\footnotetext{
${ }^{*}$ Corresponding author. E-mail: bstan@polyu.edu.hk
}

significant manufacturing factories in Hong Kong. The new completions for industrial buildings in recent years are zero, as shown in Fig. 1. Some buildings became obsolete. In 2009, the vacancy of private flatted factories exceeded 1.3 million square metres, or $8 \%$ of the total stock (Rating and Valuation Department 2010).

Furthermore, the built environment is responsible for $40 \%$ of world materials usage, a third of energy consumed by the world economy and 40\% of greenhouse gas emissions (Worldwatch Institute 1995). New construction adds less than $2 \%$ per annum to the built environment stock in Hong Kong (Langston et al. 2008). Greenhouse gas emissions 


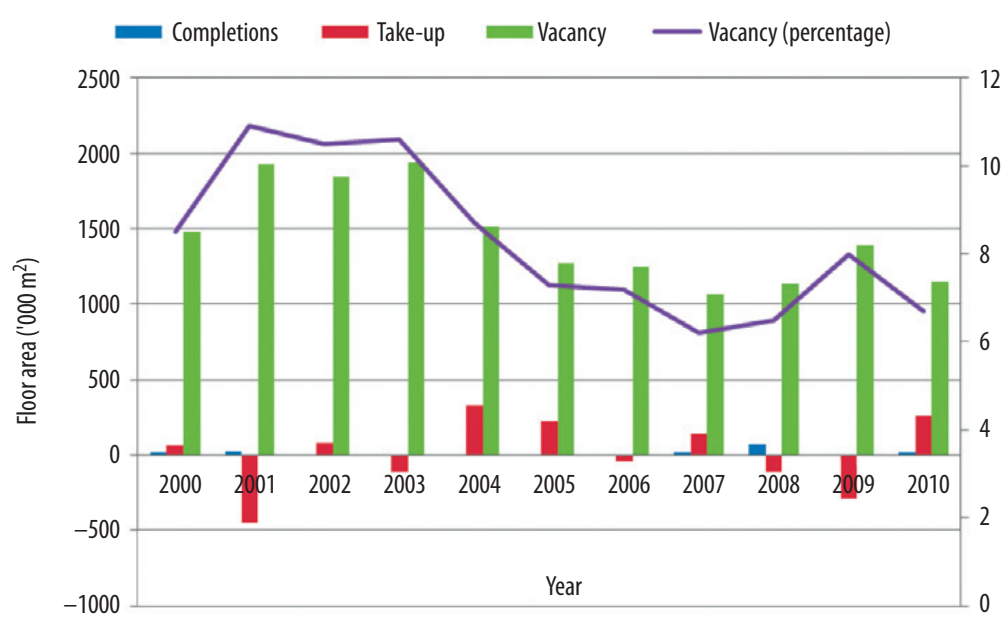

Fig. 1. Completions, take-up and vacancy of private flatted factories (2000-2010) Source: Hong Kong property review 2005-2011.

(GGE) in Hong Kong are nearing 50 million tonnes $\left(\mathrm{CO}_{2}\right.$ equivalent) per annum (http://www.epd.gov. $\mathrm{hk} /$ ) and Hong Kong is considered to be the largest producer of GGE per square metre in the world (Yung 2007). Adaptive reuse of industrial buildings can decrease new building construction with faster project delivery time and make corresponding contributions to GGE reduction, and the need for building adaptation is increasing with relevant policy drivers, such as the ' 1200 building program' developed by the City of Melbourne (Wilkinson, Reed 2011), and 'Wholesale Conversion of Industrial Buildings' scheme in Hong Kong (HKSAR, 2009). Therefore, it is an opportunity for stakeholders to think about how to reuse their buildings to meet economical, environmental and social needs. The paper aims to: (1) examine the adaptive reuse potential of industrial buildings in Hong Kong; (2) develop a fuzzy decision making method for adaptive reuse of industrial buildings, and (3) demonstrate its application in practice via a hypothetical case study.

\section{LITERATURE REVIEW OF ADAPTIVE REUSE}

With economic and social development, existing buildings may be obsolete or rapidly approach disuse and potential demolition. These buildings can be considered as raw materials for new projects, a concept described by Chusid (1993) as 'urban ore'. A more effective method is to leave the basic structure and fabric of the building intact, and change its use, rather than extracting these raw materials during demolition or deconstruction. This approach is called 'adaptive reuse'. Adaptive reuse is a special form of refurbishment that poses quite difficult challenges for designers. Changing the functional classification of a building will introduce new regulatory conditions and perhaps require zoning consent. In some cases, increases in floor space ratios can be obtained and concessions received for pursuing government policy directions by regenerating derelict public assets. There are clear economic, environmental and social benefits that can make this option attractive to developers (Langston et al. 2008). In recent years, redundant city office buildings have been converted into high quality residential apartments, bringing people back to cities and in the process revitalizing them. In Hong Kong, the Urban Renewal Authority plays an important role in overseeing such projects (http://www.ura.org.hk).

Adaptive reuse has been successfully applied in many types of facilities, including defence estates (e.g. Doak 1999; van Driesche, Lane 2002), airfields (e.g. Gallent et al. 2000), government buildings (e.g. Abbotts et al. 2003), and industrial buildings (e.g. Ball 1999; Cantell 2005; Sustainability Victoria 2006; Wilson 2010). Adaptive reuse of buildings is seen as fundamental to sound government policy and sustainable development, e.g. in Atlanta, USA (Newman 2001), Canada (Brandt 2006), Hong Kong (Poon 2001), and Australia (McLaren 1996; Maggs 1999).

Morrissey et al. (2012) argued that decisionmakers in the built environment were increasingly considering environmental and social issues alongside functional and economic aspects of development projects. Infrastructure projects in particular represent major investment and construction initiatives with attendant environmental, economic and societal impacts across multiple scales. For this reason, unmasking costs can provide strong incentives for a transition to more sustainable en- 
ergy practices, less profligate use of new materials, and greater utilization of existing building stock. Refurbishment is also a better employment generator than new construction due to the labour intensive nature of adaptation (Kincaid 2002). Further, Ürge-Vorsatz et al. (2010) found in Hungary that, given the same investment, the direct employment impacts of renovations in buildings are much higher than those in transport infrastructural developments.

Much research has been done on how existing buildings can be adapted from different stakeholder perspectives, such as developer, designer, planner, and government. Government plays an active role in building adaptive reuse, not only in regulation, but also in expanding knowledge of the sustainable development of cities (Kincaid 2000). Adaptive reuse of existing buildings, especially older buildings, attracts those creative and risk-taking investors who can make higher returns by innovative building renovation (Shipley et al. 2006). For developers, adaptive reuse of redundant structures also provides a quick solution when they are searching space for a project (Henehan et al. 2004). The concept of sustainability should be integrated into the adaptive reuse of buildings with innovative green designs (Fournier, Zimnicki 2004). Furthermore, an adaptive reuse potential (ARP) model has been developed by Langston et al. (2008). By using this model, existing buildings can be ranked according to the potential they offer for adaptive reuse. Where the current building age is close to and less than the useful life, the model identifies that planning should commence.

The selection of adaptive reuse opportunities is a difficult task for decision-makers, including government, owners, investors, developers or consultants, as they have different objectives. For an optimal selection, multiple criteria should be used and decision-makers should consider different interest groups. Wang and Zeng (2010) proposed a method for reuse selection of historic buildings using two steps: initial screening and final selection by an ANP-based approach. Pair-wise comparison is used in the ANP model, which is generally time consuming. Moreover, it may be confusing for even professionals to compare the importance of different criteria. Highest and best use method is also frequently used for real estate appraisal. However, this method is normally used to maximize the productive use for generating the highest profit. For adaptive reuse, the economic factor may not be the first. In some cases, the environmental and social factors are more important. There is a need to de- velop a new method to incorporate stakeholders' opinion by considering multiple selection criteria.

\section{ADAPTIVE REUSE POTENTIAL OF INDUSTRIAL BUILDINGS IN HONG KONG}

With the relocation of traditional manufacturing activities to the Mainland, an amount of industrial floor space in Hong Kong has been converted to office and storage uses. However, there are still many private flatted industrial buildings under-utilised. At the end of 2010, the total stock of private flatted factories in Hong Kong was around 17.2 million square metres with a vacancy rate of $6.7 \%$. Furthermore, $70 \%$ of existing industrial buildings are now situated in non-industrial zones, mainly in the "Other Specified Uses (Business)" zone (Development Bureau 2011). Most of the vacant industrial buildings are relatively young, located in urban areas with good and improving access and connectivity, and furnished with large floor plates, high ceilings, strong floor loadings, wide corridors and large lifts (Legislative Council 2011). The possible uses permitted in industrial buildings before and after redevelopment or wholesale conversion in OU(B) zones are shown in Table 1 (Development Bureau 2011).

However, the conversion of existing industrial buildings for other uses remains slow. There were only 37 cases in $\mathrm{OU}(\mathrm{B})$ zone that completed lease modifications for change of use of industrial buildings between 2001 and 2009, and only three cases involved wholesale conversion, so detailed case studies in Hong Kong are rare. Non-compliant uses of industrial buildings are widespread (Development Bureau 2011) with mixed usage of buildings due to increased rental and purchase office and residential property prices. The conversion of existing industrial buildings is an immediate solution to the problem, and there are many successful cases overseas which could be good references for Hong Kong. Furthermore, the concept of sustainability can be extended to innovative adaption of industrial buildings with creative solutions in line with current building legislation (RICS 2009). The key issues for adaptive reuse of industrial buildings include health \& safety, multi-ownership, deeds of mutual covenant, fire safety, environmental challenges, planning interface, sustainability, financial viability, building regulations, parking, districtwide implications, and enforcement (RICS 2009).

Above all, there is great potential for adaptive reuse of existing industrial buildings in Hong Kong. Another question raised is 'how to reuse?' as 
Table 1. Uses always permitted in buildings in OU(B) zones

\begin{tabular}{|c|c|}
\hline Industrial or industrial-office buildings & $\begin{array}{l}\text { Other buildings (including redeveloped or buildings } \\
\text { undergone wholesale conversion) }\end{array}$ \\
\hline $\begin{array}{l}\text { Office uses } \\
\text { - Office (excluding those involving direct provision of cus- } \\
\text { tomer services or goods) }\end{array}$ & $\begin{array}{l}\text { Office uses } \\
\text { - Office }\end{array}$ \\
\hline \multirow[t]{3}{*}{$\begin{array}{l}\text { Commercial uses } \\
\text { - Eating place (canteen only) } \\
\text { - Shop and services (motor-vehicle showroom on ground floor } \\
\text { and service trades only) }\end{array}$} & $\begin{array}{l}\text { Commercial uses } \\
\text { - Eating place } \\
\text { - Shop and services } \\
\text { - Exhibition or convention hall }\end{array}$ \\
\hline & $\begin{array}{l}\text { Recreation and leisure uses } \\
\text { - Place of entertainment } \\
\text { - Place of recreation, sports or culture } \\
\text { - Private club }\end{array}$ \\
\hline & $\begin{array}{l}\text { Educational and religious uses } \\
\text { - Educational institution } \\
\text { - Library } \\
\text { - School (excluding free-standing purpose-designed } \\
\text { building and kindergarten) } \\
\text { - Training centre } \\
\text { - Religious institution }\end{array}$ \\
\hline $\begin{array}{l}\text { Industrial uses } \\
\text { - Information technology and telecommunications } \\
\text { industries } \\
\text { - Non-polluting industrial use (excluding industrial under- } \\
\text { takings involving use/storage of dangerous goods) } \\
\text { - Research, design and development centre }\end{array}$ & $\begin{array}{l}\text { Industrial uses } \\
\text { - Information technology and telecommunications } \\
\text { industries } \\
\text { - Non-polluting industrial use (excluding industrial un- } \\
\text { dertakings involving use/storage of dangerous goods) } \\
\text { - Research, design and development centre }\end{array}$ \\
\hline
\end{tabular}

- Warehouse (excluding dangerous goods)

Source: Development Bureau (2011).

there are many factors affecting decision-making, and there are potential complaints from the public concerning commercial adaptive reuses without proper consideration of environmental and social impacts.

For adaptive reuse decision-making for buildings, multiple criteria are necessary for the assessment, including economic, social and environmental attributes. Obsolescence of existing buildings can be assessed using seven aspects, including physical, economic, functional, technological, social, legal and political (Langston 2008). Murtagh (2006) suggested the following factors for adaptive reuse selection: potential market, location, physical analysis, architectural and historical evaluation. The Architectural Institute of Japan (2007) proposed five values as criteria for building assessment, preservation and utilization, including historic value, cultural and artistic value, technological value, scenic/contextual value and the environmental effect, social value. Wang and Zeng (2010) identified six criteria for reuse selection of historic buildings based on fuzzy Delphi method, including cultural, economic, architectural, environmental, social aspect and continuity. Wang and Jiang (2007) examined the adaptive reuse of historical industrial buildings in China from different perspectives, including architecture, resources and economy, social development, environment, landmark and landscape. Wilson (2010) developed evaluating criteria for adaptive reuse selection of industrial buildings in Toronto with five adaptive reuse characteristics, including environmental, location, legislative, financial and market characteristics. Wilkinson and Reed (2011) identified 3 principle components for commercial building adaptations, namely physical and size, land and social, and found that the relationship between building adaptations and building attributes is complex. Langston and Smith (2012) developed a decisionmaking cube called iconCUR for making decisions about existing buildings, including applicability and prioritization for adaptive reuse.

Based on the above and related literature, multiple selection criteria for industrial building adaptive reuse are summarized in Table 2. Changes could be made to the criteria for specific building types.

\section{METHODOLOGY}

\section{Fuzzy set theory}

Generally, decision-making problems are made under uncertainty, vagueness, fuzziness, risk, time pressure, and some information is either incom- 
Table 2. Selection criteria of adaptive reuse industrial building

\begin{tabular}{ll}
\hline Criteria & Description \\
\hline C1: Architectural & $\begin{array}{l}\text { Physical condition, architectural evaluation; structural analysis; functional changeability, tech- } \\
\text { nological difficulties; material and decoration; refurbishment feasibility; functional performance }\end{array}$ \\
C2: Economic & Potential market; benefit-cost ratio; life-cycle cost; financial sources; subsidize; exemption \\
C3: Environmental & Site layout; environmental impact; environmental quality of surroundings; energy usage \\
C4: Social & Compatibility with existing; public interest and support; social value; enhancing community; \\
& loss of habitat \\
C5: Legal & Outline Zoning Plan (OZP); Development Permission Area (DPA) Plans; new policy measures to \\
& revitalizing industrial buildings; Wholesale Conversion of Industrial Buildings \\
\hline
\end{tabular}

plete or missing. Decision makers prefer to describe their feeling in the fuzzy terms of "good", "fair", "poor", etc. For attribute weighting, decision-makers can use fuzzy terms such as "very important", important", "moderate", "low" and "very low" to express their opinions. These fuzzy terms can be expressed by fuzzy sets or fuzzy numbers. A fuzzy set is characterized by its membership function (Zadeh 1965). The typical definitions of fuzzy theory are as follows:

Definition 1 (Zimmermann 2001). A triangular fuzzy number $\tilde{A}\left(a_{l}, a_{m}, a_{u}\right)$ can be defined as follows:

$$
\mu_{\tilde{A}}(A)=\left\{\begin{array}{lr}
0, & a \leq a_{l}, \\
\left(a-a_{l}\right) /\left(a_{m}-a_{l}\right), & a_{l} \leq a \leq a_{m}, \\
1, & a=a_{m}, \\
\left(a_{u}-a\right) /\left(a_{u}-a_{m}\right), & a_{m} \leq a \leq a_{u}, \\
0, & a \geq a_{u},
\end{array}\right.
$$

where: $a_{l}, a_{m}, a_{u}$ stand for the left bound value, mean value, and right bound value respectively in the distribution of a triangular fuzzy number, as shown in Fig. 2.

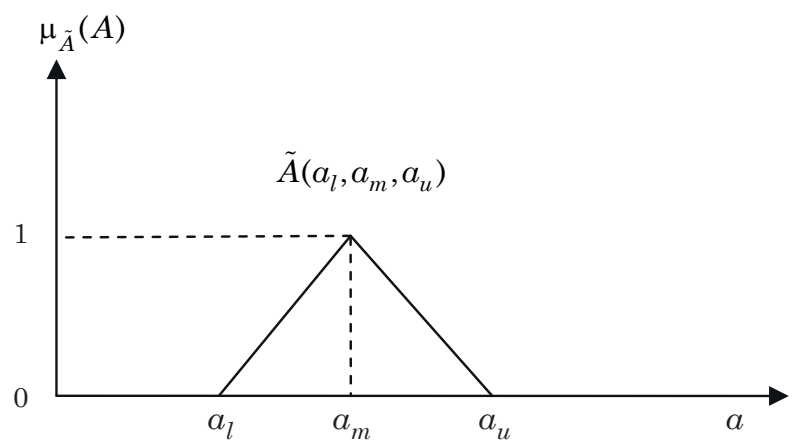

Fig. 2. Membership function $\mu_{\tilde{A}}(A)$ in a triangular fuzzy number $\tilde{A}\left(a_{l}, a_{m}, a_{u}\right)$

Definition 2 (van Laarhoven, Pedrycz 1983). Let $\tilde{A}=\left[a_{l}, a_{m}, a_{u}\right]$ and $\tilde{B}=\left[b_{l}, b_{m}, b_{u}\right]$ be two triangular fuzzy numbers, then:

$$
\begin{aligned}
& \tilde{A}(+) \tilde{B}=\left[a_{l}+b_{l}, a_{m}+b_{m}, a_{u}+b_{u}\right] ; \\
& \tilde{A}(-) \tilde{B}=\left[a_{l}-b_{u}, a_{m}-b_{m}, a_{u}-b_{l}\right] ; \\
& \tilde{A}(\times) \tilde{B} \cong\left[a_{l} b_{l}, a_{m} b_{m}, a_{u} b_{u}\right] ; \\
& \tilde{A}() \tilde{B} \cong\left[a_{l} / b_{u}, a_{m} / b_{m}, a_{u} / b_{l}\right] .
\end{aligned}
$$

The approximation is used for multiplication and division of triangular fuzzy numbers. This approximation is also used in many studies (e.g. Chen, Hwang 1992; Cheng, Lin 2002; Li et al. 2007).

Definition 3 (Heilpern 1997). Let $\tilde{A}=\left[a_{l}, a_{m}, a_{u}\right]$ and $\tilde{B}=\left[b_{l}, b_{m}, b_{u}\right]$ be two triangular fuzzy numbers, the distance between $\tilde{a}$ and $\tilde{b}$ is defined as:

$$
d(\tilde{A}, \tilde{B})=\left\{\begin{array}{l}
\left(\frac{1}{3}\left(\left|a_{l}-b_{l}\right|^{p}+\left|a_{m}-b_{m}\right|^{p}+\left|a_{u}-b_{u}\right|^{p}\right)\right)^{1 / p}, \\
1 \leq p<\infty, \\
\max \left(\left|a_{l}-b_{l}\right|,\left|a_{m}-b_{m}\right|,\left|a_{u}-b_{u}\right|\right), \\
p=\infty .
\end{array}\right.
$$

When $p=2$, formula (3) is similar to the Euclidean distance measurement and it is most commonly used, reasonable and practicable for distance measurement of fuzzy triangular numbers.

An appropriate linguistic variable set can help decision-makers make correct judgments concerning options. The linguistic terms and corresponding membership functions can be elicited from expert assessment and past data, and can be modified to incorporate individual situations. The triangular fuzzy number is the simplest fuzzy number and is used most frequently for expressing the linguistic terms in research (Chen 2000; Deng 2006). In this study, the linguistic terms are defined for a demonstration based on previous studies (Chen 2000; Lin, Chen 2004; Li et al. 2007), as shown in Tables 3 and 4. For example, if one decision-maker gives his/her opinion on the weighting of attribute 'Economic' as 'High', his/her judgment can be expressed as a fuzzy number $(0.7,0.9,1.0)$. 
Table 3. Linguistic terms describing attribute weightings

\begin{tabular}{ll}
\hline $\begin{array}{l}\text { Linguistic terms for } \\
\text { weightings }\end{array}$ & Triangular fuzzy numbers \\
\hline Very Low (VL) & $(0,0,0.1)$ \\
Low (L) & $(0,0.1,0.3)$ \\
Medium Low (ML) & $(0.1,0.3,0.5)$ \\
Medium (M) & $(0.3,0.5,0.7)$ \\
Medium High (MH) & $(0.5,0.7,0.9)$ \\
High (H) & $(0.7,0.9,1.0)$ \\
Very High (VH) & $(0.9,1.0,1.0)$ \\
\hline
\end{tabular}

Table 4. Linguistic terms describing ratings

\begin{tabular}{ll}
\hline Linguistic terms for ratings & Triangular fuzzy numbers \\
\hline Very Poor (VP) & $(0,0,1)$ \\
Poor (P) & $(0,1,3)$ \\
Medium Poor (MP) & $(1,3,5)$ \\
Fair (F) & $(3,5,7)$ \\
Medium Good (MG) & $(5,7,9)$ \\
Good (G) & $(7,9,10)$ \\
Very Good (VG) & $(9,10,10)$ \\
\hline
\end{tabular}

\section{FUZZY ADAPTIVE REUSE SELECTION MODEL}

There are various options for adaptive reuse of industrial buildings, and these can be denoted as $X=\left\{x_{1}, x_{2}, \ldots, x_{n}\right\}$. Each alternative can be assessed by the identified selection criterion $G=\left\{G_{1}, G_{2}, \ldots, G_{s}\right\}$. Then a decision-making committee is formed, denoted as $D=\left\{d_{1}, d_{2}, \ldots, d_{t}\right\}$. The committee normally should comprise key project stakeholders including appropriate community representation. According to Tables 3 and 4, the importance of the criteria and rating of alternatives with respect to each attribute are assessed by committee members. $\tilde{A}^{(k)}=\left(\tilde{a}_{i j}^{(k)}\right)_{s \times n}$ is a fuzzy decision matrix describing the rating of alternatives, where $\left(\tilde{a}_{i j}^{k}\right)_{s \times n}=\left[a_{l i j}^{k}, a_{m i j}^{k}, a_{u i j}^{k}\right]$ is an attribute value given by decision maker $d_{k} \in D$, for alternative $x_{j} \in X$ with respect to attribute $G_{i} \in G$, and $w=\left(w_{1}, w_{2}, \ldots, w_{s}\right)^{T}$ is the weight vector of attributes, where $w_{i} \geq 0, i=1,2, \ldots, s$. Then, the decision makers' assessments can be aggregated by an operator and the fuzzy adaptive reuse value (FARV) of each alternative can be denoted as:

$$
F A R V_{j}=\sum_{i=1}^{s} \tilde{w}_{i} \otimes \tilde{r}_{i j}
$$

where: $\tilde{r}_{i j}$ is the normalized fuzzy rating of alternative $x_{j} \in X$ with respect to attribute $G_{i} \in G$.
The calculation of $\tilde{r}_{i j}$ will be introduced in the next section. Then, the FARV of each alternative can be ranked.

\section{APPLICATION OF FUZZY ADAPTIVE REUSE SELECTION MODEL}

Adaptive reuse decision-making is more complex than expected by considering multi-criteria. The fuzzy approach provides a solution to integrate opinions from various parties. Here is an example for demonstrating the application of the fuzzy adaptive reuse selection model. A private 15-storey industrial building, completed in the 1980s and located in the waterfront Yau Tong Bay of Hong Kong, is selected as a hypothetical case study ${ }^{1}$ to illustrate the proposed model. The building is a reinforced concrete frame structure with windows on only two opposite faces, one facing the bay. The total floor area of the building is 50,000 square metres, and the ceiling height of a typical floor is $3095 \mathrm{~mm}$. There are 2 passenger lifts and 5 service lifts, and a central air conditioning system. This building is used for small offices and storage areas (mainly timber and other construction materials). The vacancy of the building is $70 \%$ at present. The building is representative as there are many similar buildings in Hong Kong. In order to reduce the environmental and social impact, the owner is considering adaptive reuse of the building instead of demolishing it for a new building. The decision process is as follows:

Step 1: Forming decision making committee and initial screening

In this case, a committee was formed comprising six members, including owner of the building, investor, government department, architect, surveyor and structural engineer. Committee members are to be involved in the whole decisionmaking process. Normally, the decision-making process takes several weeks. According to Legislative Council (2011) Brief, the permitted non-industrial uses in buildings within the "Commercial" Zone include office, commercial uses (including hotel, shop and services), recreation and leisure uses, educational and religious uses, Government, Institution or Community (GI/C) uses, and residential uses (subject to planning permission from town planning boards). With initial screening by

1 A hypothetical scenario is used as the case study, and although based on an actual site, is not an active adaptive reuse project. It is nevertheless representative of typical industrialised building reuse opportunities in Hong Kong. 
the committee, the possible options for the adaptive reuse of this industrial building are defined, including fashion design industrial centre (A1), luxury serviced apartment (A2), a 4-star hotel and retail centre (retail centre on lower floors) (A3), prestige office and shopping centre (shops on lower floors) (A4), or vocational education and training centre (A5). These options are based on the highest and best use for the site within the context of retaining a significant amount of the existing structure.

\section{Step 2: Assessing each alternative}

Before assessment, a comprehensive survey should be conducted, including as-built survey of the site, building context, structural and environmental components of the building, mechanical systems, safety and accessibility, and energy savings (Brownfield News 2007). The committee members should undertake a site visit. Then, the committee members assess each alternative using the criteria defined in Table 2. A summary of the ratings and weighting from all members is shown in Table 5. In some cases, the importance of decision-makers should be considered.

Step 3: Aggregating weightings and ratings

Aggregate the fuzzy decision matrices $\tilde{A}^{(k)}=\left(\tilde{a}_{i j}^{(k)}\right)_{s \times n}$ into a complex fuzzy decision matrix $\tilde{A}=\left(\tilde{a}_{i j}\right)_{s \times n}=\left[a_{l i j}, a_{m i j}, a_{u i j}\right]_{s \times n}$, and aggregate the attribute weights $\tilde{w}_{i}^{k}=\left[w_{l i}^{k}, w_{m i}^{k}, w_{u i}^{k}\right]$ into the complex attribute weights $\tilde{w}_{i}=\left[w_{l i}, w_{m i}, w_{u i}\right]$. The mean operator is normally used for aggregating decision-makers' opinion on attribute ratings and weightings (Chen 2000; Chu 2002). The average fuzzy ratings $\tilde{a}_{i j}$ and average fuzzy weightings $\tilde{w}_{i}$ of attribute $G_{i}$ can be evaluated by:

$$
\begin{aligned}
& \tilde{a}_{i j}=\frac{1}{t}\left[\tilde{a}_{i j}^{1} \oplus \tilde{a}_{i j}^{2} \oplus \ldots \oplus \tilde{a}_{i j}^{t}\right], \\
& i=1,2, \ldots, s, \quad j=1,2, \ldots, n, \\
& \tilde{w}_{i}=\frac{1}{t}\left[\tilde{w}_{i}^{1} \oplus \tilde{w}_{i}^{2} \oplus \ldots \oplus \tilde{w}_{i}^{t}\right], \\
& i=1,2, \ldots, s .
\end{aligned}
$$

The fuzzy decision matrix and the fuzzy weight of criteria are formulated by converting the linguistic terms into triangular fuzzy numbers according to Tables 3 and 4 . The complex decision matrix and weighting matrix are shown in Table 6.

Step 4: Normalizing the complex fuzzy decision matrix

To ensure compatibility between averaged ratings, the complex fuzzy decision matrix $\tilde{A}=\left(\tilde{a}_{i j}\right)_{s \times n}=\left[a_{l i j}, a_{m i j}, a_{u i j}\right]_{s \times n}$ is normalized into a corresponding matrix $\tilde{R}^{(k)}=\left(\tilde{r}_{i j}^{(k)}\right)_{s \times n}$, where

\begin{tabular}{|c|c|c|c|c|c|c|}
\hline \multirow[t]{2}{*}{ Criteria } & \multirow[t]{2}{*}{ Weightings } & \multicolumn{5}{|c|}{ Ratings (linguistic term) } \\
\hline & & $\mathrm{A} 1$ & $\mathrm{~A} 2$ & A3 & $\mathrm{A} 4$ & A5 \\
\hline $\mathrm{C} 1$ & $\begin{array}{l}\text { M; ML; M; ML; } \\
\text { ML; M }\end{array}$ & $\begin{array}{l}\text { G; VG; G } \\
\text { G; F; MG }\end{array}$ & $\begin{array}{l}\text { F; MG; G F; } \\
\text { MG; MG }\end{array}$ & $\begin{array}{l}\text { G; VG; G MG; } \\
\text { F; G }\end{array}$ & $\begin{array}{l}\text { MG; G; F MG; } \\
\text { F; MG }\end{array}$ & $\begin{array}{l}\text { G; F; F MG; } \\
\text { MG; F }\end{array}$ \\
\hline $\mathrm{C} 2$ & $\begin{array}{l}\mathrm{H} ; \mathrm{H} ; \mathrm{H} \\
\mathrm{VH} ; \mathrm{VH} ; \mathrm{H}\end{array}$ & $\begin{array}{l}\text { F; MP; F MP; } \\
\text { P; F }\end{array}$ & $\begin{array}{l}\text { G; MG; G F; } \\
\text { MG; G }\end{array}$ & $\begin{array}{l}\text { G; VG; G VG; } \\
\text { G; MG }\end{array}$ & $\begin{array}{l}\text { F; F; F } \\
\text { MG; MP; F }\end{array}$ & $\begin{array}{l}\text { F; MG; F } \\
\text { F; F; F }\end{array}$ \\
\hline C3 & $\begin{array}{l}\text { MH; H; M } \\
\mathrm{H} ; \mathrm{M} ; \mathrm{M}\end{array}$ & $\begin{array}{l}\mathrm{F} ; \mathrm{F} ; \mathrm{MG} \\
\mathrm{F} ; \mathrm{F} ; \mathrm{F}\end{array}$ & $\begin{array}{l}\text { MG; MG; G; F; } \\
\text { F; G }\end{array}$ & $\begin{array}{l}\text { G; MG; G MG; } \\
\text { F; MG }\end{array}$ & $\begin{array}{l}\text { F; MG; F } \\
\text { MG; F; F }\end{array}$ & $\begin{array}{l}\text { F; MG; F } \\
\text { F; F; MG }\end{array}$ \\
\hline $\mathrm{C} 4$ & $\begin{array}{l}\mathrm{H} ; \mathrm{H} ; \mathrm{M} \\
\mathrm{M} ; \mathrm{MH} ; \mathrm{M}\end{array}$ & $\begin{array}{l}\text { MP; P; F } \\
\text { MP; P; F }\end{array}$ & $\begin{array}{l}\text { MG; G; G MG; } \\
\text { G; G }\end{array}$ & $\begin{array}{l}\text { G; MG; G MG; } \\
\text { F; G }\end{array}$ & $\begin{array}{l}\text { G; MG; G MG; } \\
\text { F; G }\end{array}$ & $\begin{array}{l}\text { F; MG; F MG; } \\
\text { F; MP }\end{array}$ \\
\hline C5 & $\begin{array}{l}\mathrm{H} ; \mathrm{M} ; \mathrm{MH} \\
\mathrm{M} ; \mathrm{M} ; \mathrm{MH}\end{array}$ & $\begin{array}{l}\text { MG; G; G MG; } \\
\text { MG; F }\end{array}$ & $\begin{array}{l}\text { F; MG; F MG; } \\
\text { F; F }\end{array}$ & $\begin{array}{l}\text { F; MG; F MG; } \\
\text { F; MP }\end{array}$ & $\begin{array}{l}\mathrm{P} ; \mathrm{MP} ; \mathrm{F} \mathrm{MP} \\
\mathrm{P} ; \mathrm{F}\end{array}$ & $\begin{array}{l}\text { F; MP; F MG; } \\
\text { F; F }\end{array}$ \\
\hline
\end{tabular}

$$
\tilde{r}_{i j}=\left(\frac{a_{l i j}}{a_{u i}^{*}}, \frac{a_{m i j}}{a_{u i}^{*}}, \frac{a_{u i j}}{a_{u i}^{*}}\right), \quad i \in B ;
$$

Table 5. Summary of ratings and weighting for each alternative from professionals

Table 6. The averaged fuzzy weightings and ratings of three projects

\begin{tabular}{lllllll}
\hline Criteria & Weightings & \multicolumn{2}{l}{ Ratings } & & & \\
\cline { 3 - 7 } & & A1 & A2 & A3 & A4 & A5 \\
\hline C1 & $(0.2,0.4,0.6)$ & $(6.3,8.2,9.3)$ & $(4.7,6.7,8.5)$ & $(6.3,8.2,9.3)$ & $(4.7,6.7,8.5)$ & $(4.3,6.3,8.2)$ \\
C2 & $(0.77,0.93,1)$ & $(1.8,3.7,5.7)$ & $(5.7,7.7,9.2)$ & $(7.3,9,9.8)$ & $(3,5,7)$ & $(3.3,5.3,7.3)$ \\
C3 & $(0.47,0.67,0.83)$ & $(3.3,5.3,7.3)$ & $(5,7,8.7)$ & $(5.3,7.3,9)$ & $(3.7,5.7,7.7)$ & $(3.7,5.7,7.7)$ \\
C4 & $(0.47,0.67,0.83)$ & $(1.3,3,5)$ & $(6.3,8.3,9.7)$ & $(5.7,7.7,9.2)$ & $(5.7,7.7,9.2)$ & $(3.3,5.3,7.3)$ \\
C5 & $(0.43,0.63,0.82)$ & $(5.3,7.3,9)$ & $(3.7,5.7,7.7)$ & $(3.3,5.3,7.3)$ & $(1.3,3,5)$ & $(3,5,7)$ \\
\hline
\end{tabular}




$$
\begin{aligned}
& \tilde{r}_{i j}=\left(\frac{a_{l i}^{-}}{a_{u i j}}, \frac{a_{l i}^{-}}{a_{m i j}}, \frac{a_{l i}^{-}}{a_{l i j}}\right), \quad i \in C ; \\
& a_{u i}^{*}=\max _{j} a_{u i j}, \quad i \in B ; \\
& a_{l i}^{-}=\min _{j} a_{l i j}, \quad i \in C .
\end{aligned}
$$

$\mathrm{B}$ and $\mathrm{C}$ are the set of benefit criteria and cost criteria. In the case study, all the criteria are considered as benefit criteria. Using formulae (6) and (7), the normalized fuzzy decision matrix is determined as shown in Table 7.

Step 5: Calculate the FARV for each alternative According to Table 7, the FARV for each alternative is calculated using formula (4).

As for alternative A:

FARV $_{\mathrm{A} 1}=(0.2,0.4,0.6) \otimes(0.68,0.88,1) \oplus$ $(0.77,0.93,1) \otimes(0.18,0.38,0.58)$

$\oplus(0.47,0.67,0.83) \otimes(0.37,0.59,0.81) \oplus(0.47,0.67$, $0.83) \otimes(0.13,0.31,0.52)$

$\oplus(0.43,0.63,0.82) \otimes(0.59,0.81,1)=(0.76,1.82$, 3.1).

For other four alternatives:

FARV $_{\mathrm{A} 2}=(1.3,2.52,3.84)$,

$\mathrm{FARV}_{\mathrm{A} 3}=(1.43,2.65,3.88)$,

FARV $_{\mathrm{A} 4}=(0.87,1.92,3.22)$,

FARV $_{\text {A5 }}=(0.84,1.91,3.24)$.

For compatibility, normalization is used to keep the fuzzy number FARVj in the range of $[0$, 1] based on formula (6).

$a_{u i}^{*}=\max _{j} a_{u i j}=\max (3.1,3.84,3.88,3.22,3.24)=3.88$.

The normalized FAVRj for each alternative is calculated as follows:

NFAVR $_{\text {A1 }}=(0.76,1.82,3.1) / 3.88=(0.20,0.47$, $0.80)$,

$\mathrm{NFAVR}_{\mathrm{A} 2}=(1.3,2.52,3.84) / 3.88=(0.34,0.65$, 0.99),

$\mathrm{NFAVR}_{\mathrm{A} 3}=(1.43,2.65,3.88) / 3.88=(0.37,0.68$, $1.0)$,
$\mathrm{NFAVR}_{\mathrm{A} 4}=(0.87,1.92,3.22) / 3.88=(0.22,0.49$, $0.83)$.

$\mathrm{NFAVR}_{\text {A5 }}=(0.84,1.91,3.24) / 3.88=(0.22,0.49$, $0.84)$,

\section{Step 6: Ranking NFAVRj}

There are different approaches for ranking fuzzy numbers. Li et al. (2007) used four methods for ranking, including weight center, fuzzy number recognition, fuzzy TOPSIS, and simple defuzzification method, and found that the four methods have similar results. Therefore, the simple defuzzification method is used for a demonstration purpose. The defuzzification formula of a triangular fuzzy number is as follows (Cheng, Lin 2002):

$$
d=\left(a_{1}+2 a_{m}+a_{u}\right) / 4
$$

For the five alternatives, the defuzzification of NFAVRj is as follows:

$$
\begin{aligned}
& d_{A 1}=(0.2+2 \times 0.47+0.80) / 4=0.485, \\
& d_{A 2}=(0.34+2 \times 0.56+0.99) / 4=0.6125, \\
& d_{A 3}=(0.37+2 \times 0.68+1.0) / 4=0.6825, \\
& d_{A 4}=(0.22+2 \times 0.49+0.83) / 4=0.5075, \\
& d_{A 5}=(0.22+2 \times 0.49+0.84) / 4=0.51
\end{aligned}
$$

According to the closeness coefficient, the ranking of the five alternatives is A3, A2; A5; A4 and A1. The best choice is A3, (i.e. adaptive reuse for a 4 -star hotel and retail centre), while adaptive reuse to a luxury serviced apartment is also under consideration as its coefficient is very close to A1. Given the 'Economic' criterion has a higher weighting than other selection criteria, a 4-star hotel or a luxury serviced apartment are more attractive with higher economic benefits. The ranking will be different if the weightings are changed.

\section{SENSITIVITY ANALYSIS AND DISCUSSION}

Sensitivity analysis will be used when the decision-makers have different preferences on the five criteria. In this example case, the extreme states will be examined by assuming that only one cri-

Table 7. The averaged fuzzy weightings and normalized fuzzy decision matrix

\begin{tabular}{lllllll}
\hline Criteria & Weightings & \multicolumn{2}{l}{ Ratings } & \multicolumn{2}{l}{} \\
\cline { 3 - 7 } & & A1 & A2 & A3 & A4 & A5 \\
\hline C1 & $(0.2,0.4,0.6)$ & $(0.68,0.88,1)$ & $(0.5,0.72,0.91)$ & $(0.68,0.88,1)$ & $(0.5,0.72,0.91)$ & $(0.46,0.68,0.88)$ \\
C2 & $(0.77,0.93,1)$ & $(0.18,0.38,0.58)$ & $(0.58,0.78,0.94)$ & $(0.74,0.92,1)$ & $(0.31,0.51,0.71)$ & $(0.34,0.54,0.74)$ \\
C3 & $(0.47,0.67,0.83)$ & $(0.37,0.59,0.81)$ & $(0.56,0.78,0.97)$ & $(0.59,0.81,1)$ & $(0.41,0.63,0.86)$ & $(0.41,0.63,0.86)$ \\
C4 & $(0.47,0.67,0.83)$ & $(0.13,0.31,0.52)$ & $(0.65,0.86,1)$ & $(0.59,0.79,0.95)$ & $(0.59,0.79,0.95)$ & $(0.34,0.55,0.75)$ \\
C5 & $(0.43,0.63,0.82)$ & $(0.59,0.81,1)$ & $(0.41,0.63,0.86)$ & $(0.37,0.59,0.81)$ & $(0.14,0.33,0.56)$ & $(0.33,0.56,0.78)$ \\
\hline
\end{tabular}


terion has the maximum possible weight whereas the others have the minimum possible weights. For each state, the closeness coefficient of each alternative is calculated and the results are graphically represented in Fig. 3. Under situation 1, when 'Architectural' is considered as the most important criterion, the conversion choice could be fashion design industrial centre (A1) or a 4-star hotel (A3). Under situation 2, 'Economic', the best choice is hotel (A3). Under situation 3, 'Environmental', it will be luxury serviced apartment (A2) or hotel (A3). Under situation 4, 'Social', luxury serviced apartment (A2) is the best one. Under situation 5, 'Legal', the best choice is the fashion design industrial centre (A1). It can be seen that conversion to a 4-star hotel has the best economic performance that explains why the optimal choice is hotel in the case study. When environmental and social criteria are considered more important, conversion to serviced apartment could be a better choice. Therefore, this model provides decision-makers multiple options according to their different preferences on the criteria. The results form a valuable reference for them to make better decisions.

There are other multi-criteria decision-making methods, such as analytical hierarchy process (AHP), compromise programming (CP), multiattribute utility theory (MAUT). Each method has its own characteristics and applicability. For example, the AHP method can also be used for ranking alternatives as in this case. However, the

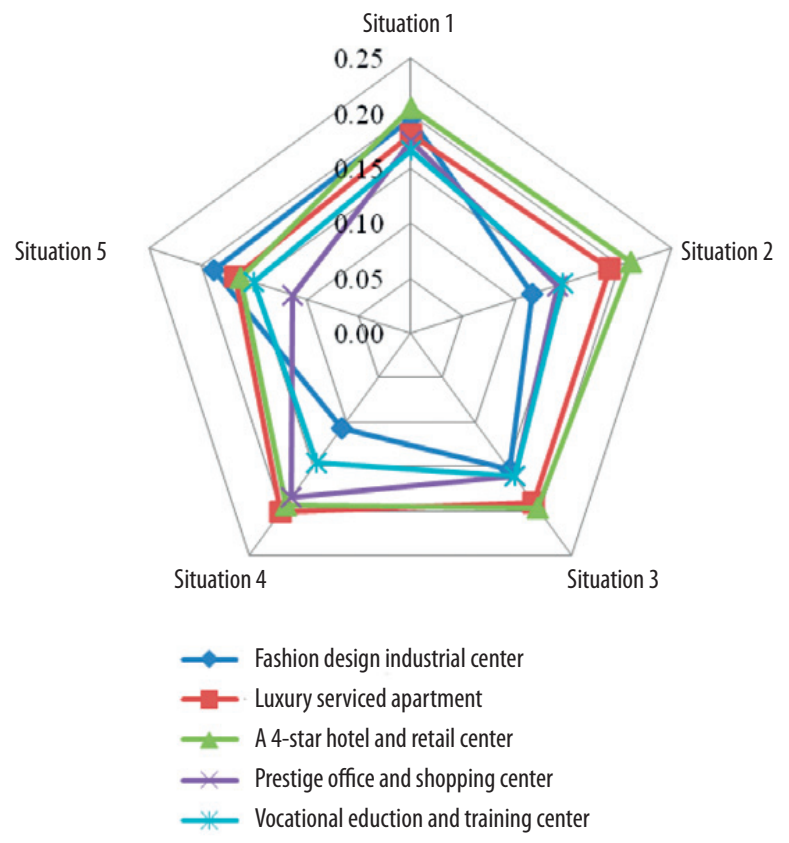

Fig. 3. Closeness coefficients of each alternative under five extreme situations pair-wise comparisons for weightings of criteria and alternatives consume lots of time. Decisionmakers might find it difficult to use the 9-point scale. By contrast, the fuzzy TOPSIS method is much easier for decision-makers by using fuzzy terms and the calculation is not complex (and can be further simplified by developing a computing package). Multiple selection criteria and decisionmakers make the assessment of each alternative comprehensive and objective. Decision-makers can also use sensitivity analysis with different criteria priorities.

\section{CONCLUSIONS}

With industrial transformation, there are many private industrial buildings vacant or under-utilised in Hong Kong. Adaptive reuse or revitalisation of these obsolete industrial buildings not only extends their life but also has great economic, social and environmental benefits if they are properly assessed. The industrial buildings in Hong Kong have a high potential for adaptive reuse with innovative sustainable designs. These buildings could be converted to residential, hotel, office, retail shops, sports centres, etc., or otherwise demolished and a new development constructed in its place. The deployment of a fuzzy approach for decision-makers in order to make better choices about reusing existing buildings will need to consider the characteristics of the building and integrate stakeholder opinions. The results provide decision-makers with valuable insight into the adaptive reuse selection problem.

In practice, however, adaptive reuse of existing industrial buildings may not reflect the highest and best use for a site. There may be social and environmental arguments for why an economic focus may be inappropriate. Where reuse is the chosen strategy, the selection process for a new functional purpose can be assisted by the approach outlined in this paper.

\section{REFERENCES}

Abbotts, J.; Ertell, K. B.; Leschine, T. M.; Takaro, T. K. 2003. Building leasing at the department of energy's Hanford site: lessons learned from commercial reuse, Federal Facilities Environmental Journal 14(1): 95-107. http://dx.doi.org/10.1002/ffej.10065

Architectural Institute of Japan. 2007. Guidelines for building assessment, preservation and utilization. Architectural Institute of Japan.

Ball, R. 1999. Developers, regeneration and sustainability issues in the reuse of vacant industrial buildings, 
Building Research and Information 27(3): 140-148. http://dx.doi.org/10.1080/096132199369480

Brandt, M. 2006. How to adaptively reuse a community asset?, Heritage: the Magazine of the Heritage Canada Foundation 9(2): 21-22.

Brownfield News. 2007, October 16. Adaptive reuse: uncovering hidden assets and obstacles. Available at: http://www.greenbiz.com/research/report/2007/10/17/ adaptive-reuse-uncovering-hidden-assets-and-obstacles

Cantell, S. F. 2005. The adaptive reuse of historic industrial buildings: regulation barriers, best practices and case studies. Master of Urban and Regional Planning thesis, Virginia Polytechnic Institute and State.

Chen, C. T. 2000. Extensions of the TOPSIS for group decision-making under fuzzy environment, Fuzzy Sets and Systems 114(1): 1-9. http://dx.doi.org/10.1016/ S0165-0114(97)00377-1

Chen, S. J.; Hwang, C. L. 1992. Fuzzy multiple attribute decision making: methods and applications. Berlin: Springer-Verlag.

Cheng, C. H.; Lin, Y. 2002. Evaluating the best main battle tank using fuzzy decision theory with linguistic criteria evaluation, European Journal of Operational Research 142(1): 174-186. http://dx.doi. org/10.1016/S0377-2217(01)00280-6

Chu, T. C. 2002. Facility location selection using fuzzy TOPSIS under group decisions, International Journal of Uncertainty, Fuzziness and Knowledge-Based Systems 10(6): 687-701. http://dx.doi.org/10.1142/ S0218488502001739

Chusid, M. 1993. Once is never enough, Building Renovation Mar-Apr: 17-20.

Deng, Y. 2006. Plant location selection based on fuzzy TOPSIS, International Journal of Advanced Manufacturing Technology 28(7-8): 839-844. http://dx.doi. org/10.1007/s00170-004-2436-5

Development Bureau. 2011. Optimising the use of industrial buildings to meet Hong Kong's changing economic and social needs. Available at: http://www. devb.gov.hk/industrialbuildings/eng/background/ optimising_land_use/index.html [accessed 20 May 2011]

Doak, J. 1999. Planning for the reuse of redundant defense estate: disposal processes, policy frameworks and development impacts, Planning Practice and Research 14(2): 211-224. http://dx.doi. org/10.1080/02697459915733

Fournier, D. F.; Zimnicki, K. 2004. Integrating sustainable design principles into the adaptive reuse of historical properties. US Army Corp of Engineers, Engineer Research and Development Center.

Gallent, N.; Howe, J.; Bell, P. 2000. New uses for England's old airfields, Area 32(4): 383-394. http://dx.doi. org/10.1111/j.1475-4762.2000.tb00154.x

Heilpern, S. 1997. Representation and application of fuzzy numbers, Fuzzy Sets and Systems 91(2): 259268. http://dx.doi.org/10.1016/S0165-0114(97)00146-2

Henehan, D.; Woodson, R. D.; Culbert, S. 2004. Building change-of-use: renovating, adapting and altering commercial, institutional and industrial properties. New York: McGraw-Hill.
HKSAR. 2009. HKSAR 2009-10 policy address: breaking new ground together. Available at: http://www. policyaddress.gov.hk/09-10/eng/index.html [accessed 18 October 2012]

Kincaid, D. 2000. Adaptability potentials for buildings and infrastructure in sustainable cities, Facilities 18(3/4): 155-161. http://dx.doi. org/10.1108/02632770010315724

Kincaid, D. 2002. Adapting buildings for changing uses: guidelines for change of use refurbishment. London: Spon Press.

Langston, C. 2008. The sustainability implications of building adaptive reuse (keynote paper), in CRIOCM2008, Oct/Nov, 2008, Beijing, 1-10.

Langston, C.; Smith, J. 2012. Modelling property management decisions using 'iconCUR', Automation in Construction 22: 406-413. http://dx.doi.org/10.1016/j. autcon.2011.10.001

Langston, C.; Wong, F. K. W.; Hui, E. C. M.; Shen, L. Y. 2008. Strategic assessment of building adaptive reuse opportunities in Hong Kong, Building and Environment 43(10): 1709-1718. http://dx.doi.org/10.1016/j. buildenv.2007.10.017

Legislative Council. 2011. Background brief on revitalization of industrial buildings, LC Paper No. CB(1)1909/10-11(07), Panel on Development - Meeting on 20 April 2011. Available at: http://www. legco.gov.hk/yr10-11/english/panels/dev/papers/ dev0420cb1-1909-7-e.pdf

Li, Y. W.; Nie, X. T.; Chen, S. Y. 2007. Fuzzy approach to prequalifying construction contractors, Journal of Construction Engineering and Management-ASCE 133(1): 40-49. http://dx.doi.org/10.1061/(ASCE)07339364(2007)133:1(40)

Lin, C. T.; Chen, Y. T. 2004. Bid/no-bid decision-making - a fuzzy linguistic approach, International Journal of Project Management 22(7): 585-593. http:// dx.doi.org/10.1016/j.ijproman.2004.01.005

Maggs, A. 1999. Adaptive reuse, In Place 1(4): 33-34.

McLaren, P. 1996. Adaptation and reuse, Monuments and Sites Australia: Australia ICOMOS. Sri Lanka National Committee of ICOMOS, 170-176.

Morrissey, J.; Iyer-Raniga, U.; McLaughlin, P.; Mills, A. 2012. A strategic project appraisal framework for ecologically sustainable urban infrastructure, Environmental Impact Assessment Review 33(1): 55-65. http://dx.doi.org/10.1016/j.eiar.2011.10.005

Murtagh, W. J. 2006. Rehabilitation and adaptive use, keep time: the history and theory of preservation in America. New Jersey, Canada: John Wiley \& Sons.

Newman, H. K. 2001. Historic preservation policy and regime politics in Atlanta, Journal of Urban Affairs 23(1): 71-86.

Poon, B. H. S. 2001. Buildings recycled - city refurbished, Journal of Architectural Education 54(3): 191-194. http://dx.doi.org/10.1162/10464880152632514

Rating and Valuation Department. 2010. Hong Kong property review 2010. Hong Kong.

RICS. 2009. Industrial buildings - strategic review of issues associated with conversion for adaptive re-use. Royal Institution of Chartered Surveyors (RICS). Available at: http://www.ricsasia.org/downloadFile. php?id=248 
Shipley, R.; Utz, S.; Parsons, M. 2006. Does adaptive reuse pay? A study of the business of building renovation in Ontario, Canada, International Journal of Heritage Studies 12(6): 505-520. http://dx.doi. org/10.1080/13527250600940181

Sustainability Victoria. 2006. Sustainable solar solutions case study 02, Melbourne, Vol. 3. Available at: www.sustainability.vic.gov.au/www/html/1589-casestudies.asp.

Ürge-Vorsatz, D.; Arena, D.; Tirado Herrero, S.; Butcher, A. C. 2010. Employment impacts of a large-scale deep building energy retrofit programme in Hungary. Prepared for the European Climate Foundation by The Center for Climate Change and Sustainable Energy Policy (3CSEP) Central European University Budapest, Hungary.

Van Driesche, J.; Lane, M. 2002. Conservation through conversation: collaborative planning for reuse of a former military property in Sauk County, Wisconsin, USA, Planning Theory and Practice 3(2): 133-153. http://dx.doi.org/10.1080/14649350220150062

Van Laarhoven, P. J. M.; Pedrycz, W. 1983. A fuzzy extension of Saaty's priority theory, Fuzzy Sets and Systems 11(1-3): 199-227. http://dx.doi.org/10.1016/ S0165-0114(83)80082-7

Wang, J. G.; Jiang, N. 2007. Conservation and adaptive-reuse of historical industrial building in China in the post-industrial era, Frontiers of Architecture and Civil Engineering in China 1(4): 474-480. http:// dx.doi.org/10.1007/s11709-007-0064-5
Wang, H. J.; Zeng, Z. T. 2010. A multi-objective decisionmaking process for reuse selection of historic buildings, Expert Systems with Applications 37(2): 12411249. http://dx.doi.org/10.1016/j.eswa.2009.06.034

Wilkinson, S. J.; Reed, R. 2011. Examining and quantifying the drivers behind alterations and extensions to commercial buildings in a central business district, Construction Management and Economics, 29(7): 725-735. http://dx.doi.org/10.1080/01446193.2 011.588954

Wilson, C. 2010. Adaptive reuse of industrial buildings in Toronto, Ontario evaluating criteria for determining building selection. Master of Urban and Regional Planning (M.PL.), Queen's University Kingston, Ontario, Canada.

Worldwatch Institute. 1995. State of the world, 1995. Worldwatch Institute, Washington.

Yung, C. 2007. Hong Kong world champion of greenhouse gas emissions, The Standard (Hong Kong newspaper), Saturday, February 17, 2007. Available at: http://www.thestandard.com.hk/news_detail. asp?pp_cat $=11 \&$ art_id $=38548 \&$ sid $=12269160 \&$ con type $=1+$ [accessed 20 May 2011]

Zadeh, L. A. 1965. Fuzzy sets, Information and Control 8(3): 338-353. http://dx.doi.org/10.1016/S00199958(65)90241-X

Zimmermann, H.-J. 2001. Fuzzy set theory and its application. $4^{\text {th }}$ ed. Kluwer Academic Publishers. 